\title{
La deshumanización del Arte de Ortega y Gasset y el papel del «hombre-masa»
}

\author{
CONSTANZA NIETO YUSTA* \\ The dehumanization of Art by Ortega y Gasset and the rol the \\ «hombre-masa»
}

\begin{abstract}
RESUMEN
El pequeño y controvertido libro de Ortega y Gasset, "La deshumanización del arte», ha de entenderse en y desde el conjunto del pensamiento del filósofo español. El análisis de su posterior ensayo «La rebelión de las masas» permite ampliar la comprensión del concepto de deshumanización desde la interpretación del arte nuevo español a lecturas de carácter sociológico que entroncan con la Escuela de Frankfurt y con figuras como Jürgen Habermas.
\end{abstract}

\author{
PALABRAS CLAVE \\ Ortega y Gasset, burguesía, \\ homogeneización, técnica, \\ deshumanización, arte
}

\begin{abstract}
The small and controversial book of Ortega y Gasset, “La deshumanización» del arte, has to be understood in the whole thought of the spanish philosopher. The analysis of his later essay, "La rebelión de las masas", allows a broader understanding of the concept of deshumanization from the interpretation of new art in Spain towards sociological readings that connect to the Frankfurt School and with philosophers such as Jürgen Habermas.
\end{abstract}

\section{KEY WORDS}

Ortega y Gasset, Bourgeoisie, Homogenization, Technique, Deshumanization, Art

En agosto de 1930, y tras la aparición de numerosos artículos en el periódico El Sol, veía la luz La rebelión de las masas aunque el texto o, tal y como es definido por el mismo autor, el «casi-libro»" , continuaría viendo ampliado su contenido durante prácticamente veinte años. Numerosos habían sido los acontecimientos que, desde poco antes de la publicación de La deshumanización del arte, estaban marcando el futuro político de Europa. Hasta 1930 pueden destacarse en Es-

\footnotetext{
${ }^{1}$ Modo en el que Ortega se refiere a La rebelión de las masas por haberse concebido como un artículo y por su ulterior desarrollo fragmentario y separado en el tiempo, pues hasta 1947 la obra sufrió numerosas modificaciones y añadidos que se materializaron en los prólogos y el epílogo que actualmente se incluyen y conocen como partes indiscutibles del libro. Ortega, asimismo, se refiere a éste como una obra abierta por ser consciente de haber planteado una problemática fundamental para el siglo XX.
} 


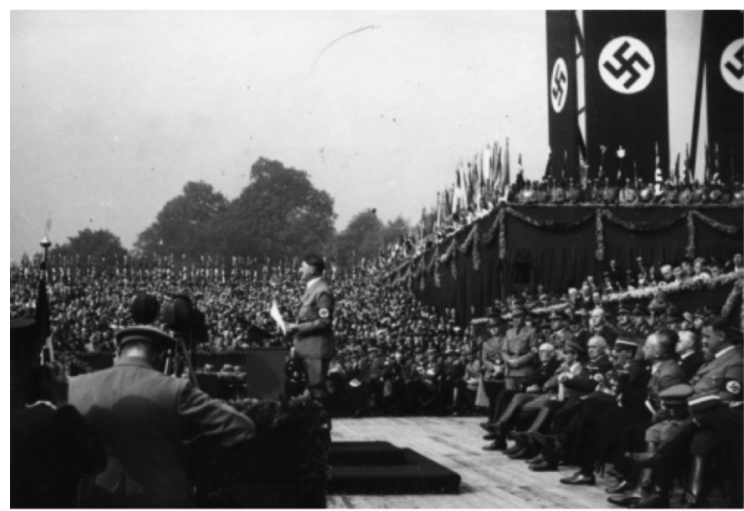

Figura 1: Hitler, recién subido al poder. 1933.

paña la instauración de la dictadura militar de Miguel de Primo de Rivera (1923), su crisis (1929) y su caída en enero de 1930, momento a partir del cual Dámaso Berenguer se encargaría de la jefatura del gobierno hasta la proclamación de la II República el 14 de abril de 1931. En Europa, cabe destacar la presencia de Benito Mussolini en el gobierno italiano desde 1922 así como la progresiva ascensión y popularización del Partido Nacionalsocialista alemán liderado por un Adolf Hitler que, poco tiempo después -en 1933-, se vería elegido canciller de la nación alemana.

En un contexto de semejante efervescencia política, la mayor parte de los intelectuales tomaron partido; ese fue el caso de Ortega que, desde el mismo Pacto de San Sebastián, mostró su adhesión al nuevo gobierno republicano del que se desvincularía definitivamente en 1932. No obstante, su «compromiso político»² continuaría a lo largo de los años siguientes a través de una incansable producción filosófica que no se vería interrumpida por la Guerra civil española que llevó al pensador a exiliarse en París, Buenos Aires y Lisboa hasta 1945, año de su regreso a España y del fin de la Segunda Guerra Mundial.

La rebelión de las masas, por tanto, no sólo responde a un contexto político imposible de obviar, sino que basa su contenido en el análisis de la situación social e ideológica que explica el mismo.

\footnotetext{
${ }^{2}$ Hay que destacar que, si bien Ortega participa en la política del momento a través de los escritos publicados sobre el tema en cuestión a lo largo de toda su trayectoria, su concepción de la política se verá a todas luces incompatible con el papel que atribuye al pensador y su labor intelectual, hasta el punto de afirmar «yo detesto toda política» y «yo no tengo nada que ver con la política». Para Ortega, mientras la labor del intelectual es facilitar la comprensión de las cuestiones que aborda, la del político, enfermo de analfabetismo, no consiste sino en confundirlas y sumirlas en la oscuridad. Semejante crítica de la política responde a la concepción que el pensador tiene sobre la clase burguesa analizada en La rebelión de las masas, predominante en todos los ámbitos sociales, muy principalmente en la política, entendida en este sentido como medio de ascensión y expresión de las masas. ORTEGA Y GASSET, José, La rebelión de las masas, Madrid, Tecnos, 2003, p.102.
} 
El ensayo está estructurado en dos partes: a lo largo de la primera, titulada del mismo modo que la totalidad del libro, Ortega procede a la disección psicológica del individuo de clase media; la segunda ${ }^{3}$ se dedica a mostrar las consecuencias negativas de la rebelión de las masas en la época contemporánea. Nuestro estudio intentará abordar de forma concisa las principales ideas que laten en el ensayo con objeto de vincularlas con aquellas que estructuraron La deshumanización del arte. Pues, es a la luz de La rebelión de las masas como el controvertido ensayo de 1925 adquiere una interpretación que supera su lectura meramente estética y que permite insertarlo en el corpus orteguiano y conectarlo con líneas de pensamiento como la representada por la Escuela de Frankfurt y con figuras como Jürgen Habermas.

\section{LA BURGUESÍA Y EL «HOMBRE-MASA»: IGUALDAD HOMOGENEIZADORA. ESTADO-MÁQUINA Y RESORTE, PROTOTIPO, INERCIA.}

La rebelión de las masas es la denominación que Ortega emplea para referirse al fenómeno más destacado del panorama contemporáneo: el ascenso de la mayoría de la población al poder social. La sociedad, por tanto, está formada por una masa que se define como «el conjunto de personas no especialmente cualificadas. No se entienda, pues, por masas sólo ni principalmente "las masas obreras". Masa es "el hombre medio" »4. La mayoría poblacional a la que se refiere Ortega estaría constituida por "hombres-masa" ${ }^{5}$, es decir, por la clase media que desde el siglo XVIII, aunque existente desde tiempo atrás, ha venido a establecerse como el estrato social predominante conocido bajo la denominación genérica de burguesía. Frente a esta mayoría - de la que ya intuimos sus rasgos diferenciales si pensamos en la clasificación que se planteaba del público en $\mathrm{La}$ deshumanización del arte-, Ortega coloca a las minorías, aquellas formadas por «individuos o grupos de individuos especialmente cualificados», «hombres selectos" ${ }^{7}$, y no por meros componentes indiferenciados por su pertenencia a un grupo. Pero procedamos a analizar al «hombre-masa» objeto del ensayo orteguiano; la sola enumeración de sus rasgos nos permitirá comprender el sentido de des-

3 «Quién manda en el mundo» en Op.cit., pp.271-350.

${ }^{4}$ Op. cit., p. 125.

${ }^{5}$ El empleo del calificativo «masa» para referirse a los hombres que componen la clase burguesa tiene unas connotaciones peyorativas obvias. Puesto que masa, en el Diccionario de la R.A.E., queda recogida como «muchedumbre o conjunto numeroso de personas», pero, asimismo, como «volumen, conjunto, reunión», "conjunto o concurrencia de algunas cosas» e incluso como «mezcla que proviene de la incorporación de un líquido con una materia pulverizada, de la cual resulta un todo espeso, blando y consistente", su aplicación a una clase social denota principalmente colectividad, homogeneización e igualdad entre todos sus miembros.

${ }^{6} \mathrm{lbid}$.

7 Op. cit., p.127. 


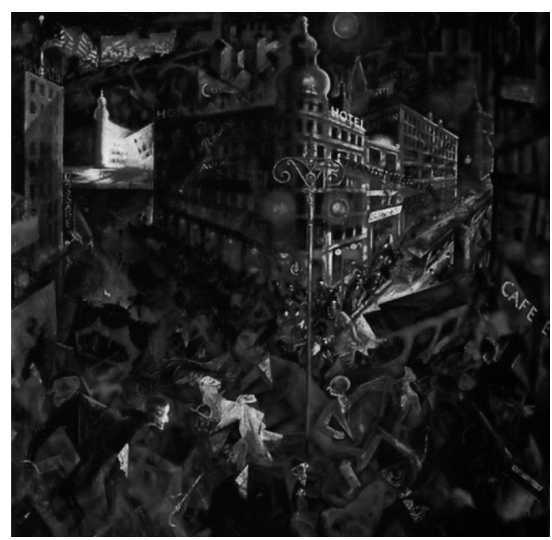

Figura 2: George Grosz, La ciudad, 1917.

humanización principal de la obra de 1925, así como entender por simple contraposición la naturaleza de la clase contraria o minoritaria.

La caracterización psicológica del «hombre-masa» comienza con su ubicación espacio-temporal en los núcleos urbanos. Es en las transformaciones urbanas de las ciudades producidas por la Revolución industrial y de la especialización técnica donde las masas conviven desde el crecimiento desmesurado de la población europea registrado hacia finales del siglo $\mathrm{XIX}^{8}$ : es éste el lugar de su reinado social, político e intelectual, es el ámbito de la vida y la opinión pública, el espacio de la igualdad democrática. Pero Ortega señala que no siempre fue así: en el pasado preindustrial «los individuos que integran estas muchedumbres preexistían, pero no como muchedumbre. Repartidos por el mundo en pequeños grupos, o solitarios, llevaban una vida, por lo visto, divergente, disociada, distante. Cada cual -individuo o pequeño grupo- ocupaba un sitio, tal vez el suyo, en el campo, en la aldea, en la villa, en el barrio de la gran ciudad ${ }^{9}$. La causa del movimiento masivo a las ciudades hay que encontrarla en el siglo XVIII: las promesas de progreso y de trabajo que estos núcleos urbanos emanaban fueron más que un aliciente para el sector rural.

La gestación del «hombre-masa», por tanto, se remonta al siglo XVIII, aunque fue en el XIX cuando alcanzó su máximo desarrollo. Fue en el Siglo de las Luces donde, junto al establecimiento de la ciudad como el espacio físico de las masas por antonomasia, fenómenos como la Revolución Francesa y la Revolución Industrial inglesa prepararon las bases psicológicas que acabarían dando lugar al carácter burgués que denuncia Ortega. Por un lado, las aspiraciones de felicidad, progreso e igualdad del proyecto racionalista francés, cuya materialización -no

\footnotetext{
${ }^{8}$ En el capítulo V, «Un dato estadístico», Ortega refuerza su tesis del imparable ascenso de las masas y de la imposibilidad de asimilación psicológica y cultural por la velocidad del mismo recurriendo a los datos demográficos recogidos por el sociológo Werner Sombart. Op. cit., pp.171-178.

${ }^{9}$ Op. cit., p.124.
} 
exenta de contradicciones- fue la Declaración de los derechos del hombre y del ciudadano de 1789, asentaron la convicción en cada uno de los hombres de la igualdad de unos respecto a otros en todos los ámbitos y revalorizaron la opinión pública con la primera democratización del conocimiento que supuso la Encyclopedie: la apertura de los Salones al gran público y el nacimiento de la crítica, por mencionar algunas de sus aportaciones más destacadas. Por otro, los avances científicos que produjo la Revolución industrial que tuvo su origen en Inglaterra, pero que pronto se extendería al resto de Europa, introdujeron la fe en el progreso técnico y en el futuro que éste auguraba, así como la especialización del trabajo. El siglo XIX se encargó de establecer definitivamente cada uno de estos ideales en la mente de una burguesía que fue, junto a las agitaciones sociales del proletariado, la indiscutible protagonista de todos los movimientos políticos del siglo encaminados a la lucha de la igualdad proclamada durante la época precedente.

El siglo XX, tal y como señala, Ortega, se encargó de convertir los ideales fraguados en los siglos XVIII y XIX en una realidad psicológica del sujeto contemporáneo, en una convicción que, para el pensador español, pierde, en tanto que real y no ideal, todos los valores en los que originariamente se asentaba. El «hombre-masa», por tanto, estaría conformado por una ideología alienada resultado de la evolución cultural y psicológica de los últimos dos siglos. Para Ortega, el factor detonante de esta mutación de los ideales originarios en convicciones mediocres se encontraría en la política, en el gobierno entendido como un títere a las órdenes de la opinión pública que lo encumbra y a través del cual el «hombre-masa» extendería los dictados de su ideología. Este sistema político al servicio de las opiniones y los "tópicos de café» 10 de las masas -que por esto mismo no son sino «boyas que van a la deriva»11 es a lo que Ortega se refiere con las expresiones “hiperdemocracia»12 y «democracia morbosa»13: la radicalización y degeneración del derecho de igualdad entre todos los hombres ha establecido por primera vez en la historia la primacía de las opiniones de la mayoría sobre los criterios de unas minorías aristocráticas que, por cuestiones de conservación social, deben liderar a la humanidad en sus intereses. En semejantes declaraciones, la referencia implícita al fracaso de la utopía igualadora de los hombres que fue la llustración es más que patente. Las preocupaciones de Ortega se dirigen más a los peligros que conlleva la homogeneización humana que a reinstaurar un sistema político-social de privilegios; su deseo es mantener la individualidad que las nuevas ciudades del desarrollo van diluyendo poco a poco y que, consecuentemente, conduce a una humanidad sin voluntad como protagonista de la historia.

El Estado es el portavoz de las masas y, por tanto, el máximo responsable de la difusión y aplicación de esta política de tan peligrosos efectos. Para recalcar el

${ }^{10}$ Op. cit., p. 130.

11 Op. cit., p. 127.

12 Op. cit., p. 131.

13 «Democracia morbosa» (El Espectador II ,1917) en ORTEGA Y GASSET, José, Obras completas, vol. II, pp.271-275. 
papel deshumanizador del Estado, Ortega recurre a su descripción en términos tecnológicos, comparando su funcionamiento con la eficiencia, mecanización y frialdad características de la sociedad industrial en que se convertiría Europa desde el siglo XVIII. «En nuestro tiempo, el Estado ha llegado a ser una máquina formidable que funciona prodigiosamente, de una maravillosa eficiencia por la cantidad y la precisión de sus medios. Plantada en medio de la sociedad, basta tocar a un resorte para que actúen sus enormes palancas y operen fulminantes sobre cualquier trozo del cuerpo social» ${ }^{14}$. El Estado, esa «portentosa máquina» ${ }^{15}$ en tanto representación eficiente de los intereses de la mayoría, tiene como máximo enemigo a las minorías, a las individualidades que constituyen la amenaza de su estabilidad; pero, su funcionamiento, en tanto máquina, es eficiente, capaz de «aplastar [...] toda minoría creadora que lo perturbe- que lo perturbe en cualquier orden: en política, en ideas, en industria» ${ }^{16}$. El Estado, por tanto, representa a una sociedad contemporánea, plenamente humana en su materialización política de los derechos democráticos, pero también en progresiva deshumanización por sus espacios de aglomeración y su sistema de trabajo despersonalizado introducidos a raíz de la industrialización inglesa. La concepción del Estado como una máquina elimina lo imprevisto, la espontaneidad en la acción, la praxis histórica por parte de los individuos puesto que éstos, subordinados al perfecto funcionamiento del todo institucional, quedan anulados, convertidos en meros engranajes, piezas de funcionamiento mecánico. He aquí, lo que preocupa a Ortega de la homogeneización resultante de la concepción igualadora de los hombres: la destrucción de su conciencia como individuos, de su capacidad para intervenir en la historia. El Estado, planteado como el mejor aliado de los hombres, como su apoyo, se ha convertido finalmente en su peor enemigo ${ }^{17}$.

¿Pero cómo es posible que el mismo hombre que ha creado semejantes mecanismos no sea capaz de percibir sus nefastas consecuencias? En la caracterización psicológica que Ortega realiza del «hombre-masa» se encuentran las respuestas.

La identificación entre la clase media que es la burguesía con las aglomeraciones y las muchedumbres necesariamente nos hace pensar en la corriente compacta e indiferenciada que recorre las ciudades contemporáneas. En esa oleada humana se inserta el «hombre-masa», un ser-prototipo repetido hasta la sa-

\footnotetext{
${ }^{14}$ Op. cit., p. 262.

${ }^{15}$ Op. cit., p 263.

${ }^{16}$ Ibid.

${ }^{17}$ En «Intimidades. El hombre a la defensiva» (El Espectador VII, 1930), Ortega se refería a la farsa del Estado empleando el símil de la ortopedia: aunque el Estado se plantea como una prolongación de las capacidades y derechos naturales del hombre que lo sustenta, esta ayuda, que no deja de ser artificial -la ortopedia-, pasa a convertirse en dependencia, en un elemento más de la anatomía de un hombre que, acostumbrado a su uso y olvidado ya de su independencia motora, agradece sus favores sin percatarse de la dificultad y coerción de sus movimientos. ORTEGA Y GASSET, José, Obras completas, vol. II, p. 738.
} 
Figura 3: Raoul Hausmann, El espíritu de nuestro tiempo, 1920.

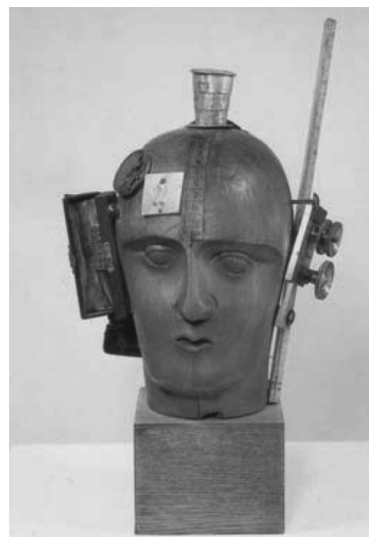

ciedad y satisfecho de su naturaleza estandarizada: la cantidad revierte en calidad, lo colectivo triunfa sobre lo individual. ${ }^{18}$

La seguridad, tanto económica como jurídica, que obtiene el «hombre-masa», la multitud, de la política y del Estado que lo representa, explica su hostilidad ante cualquier manifestación o iniciativa individual que, en tanto diferencia de los intereses colectivos, pueda convertirse en amenaza de la estabilidad que garantiza el confort y el orden público. La confianza que el «hombre-masa» deposita en este sistema burgués-capitalista que le otorga facilidades materiales, civiles y morales deriva en su actitud de conformismo y autosatisfacción, en la inercia y estatismo que caracteriza toda vida vulgar. ${ }^{19}$ La inercia, en tanto «flojedad, desidia, inacción» ${ }^{20}$, implica que, en el estadio mecánico y autocomplaciente del «hombremasa», que en los movimientos repetitivos que constituyen sus «opiniones, apetitos, preferencias o gustos», se geste un hermetismo o indocilidad hacia todo lo que no sea su mundo estático. Este estar cerrado que es el «hombre-masa» y que nos hace pensar en su ser-así como una caja, es lo que conduce a este tipo de hombre a vivir del modo menos humano posible en tanto menos digno -por su estatismo, conformismo, abandono y ensimismamiento intelectual- y a actuar en consecuencia: exigiendo obligaciones al Estado que lo sustenta pero ajeno a responsabilidades de cualquier tipo respecto al mismo ${ }^{21}$. Este carácter cerrado que Ortega señala en este hombre producto del capitalismo por excelencia que es el burgués, enlaza directamente con las teorías de Jürgen Habermas acerca de la legitimación

\footnotetext{
${ }^{18}$ ORTEGA Y GASSET, José, La rebelión de las masas, Madrid, Tecnos, 2003, pp. 125-127.

${ }^{19}$ Puesto que la vida noble es aquella que interactúa con el mundo, aquella que no se conforma y que se esfuerza en una continua superación de sí misma, la vida vulgar se caracteriza por todo lo contrario, replegándose en un estado de autosatisfacción improductiva y ajena a otro posible discurrir del mundo. Op. cit., pp.189-192.

${ }_{20}$ Según queda recogido en el Diccionario de la R.A.E. Asimismo, inercia, en su acepción mecánica, se define como la «incapacidad de los cuerpos para salir del estado de reposo, para cambiar las condiciones de su movimiento o para cesar en él, sin la intervención de alguna fuerza.»

${ }^{21}$ ORTEGA Y GASSET, José, La rebelión de las masas, Madrid, Tecnos, 2003, p.262.
} 
del poder en las sociedades tecnológico-capitalistas. Su análisis se basa en la teoría de sistemas, es decir, en la interpretación funcionalista de la sociedad como un compuesto de cajas o sistemas cerrados; una lectura que implica el determinismo social, puesto que las relaciones existentes entre estos sistemas sociales están encaminadas a legitimar el todo sistémico, determinando toda acción individual y, consecuentemente, toda política. El «hombre-masa» que analiza Ortega es resultado de esa máquina tan perfecta que es el Estado y, por tanto, hereda el funcionamiento mecánico y previsible del mismo. Esa es la flojedad, la inercia y la desidia temperamental de un hombre «caja», por seguir las lecturas habermasianas, cuyo hermetismo al servicio del correcto funcionamiento social y estatal le excluye de forma drástica de la participación política e histórica ${ }^{22}$.

Esa es la decadencia de Europa: la desmoralización que implica una vida sin responsabilidades ha degenerado en la dominación del mundo por unos muertos vivientes $^{23}$ sujetos al intervencionismo de un Estado que ellos mismos han creado como algo ajeno a su realidad, como una institución grandilocuente e intocable. Sin duda, es a esta caracterización del «hombre-masa» como un sujeto sin conciencia histórica, apolítico, a lo que se refiere Ortega cuando proclama que el espíritu de nuestro tiempo se halla sumido en la confusión que resulta de la disociación respecto del pasado pero también respecto del mismo presente. El «hombre-masa» no responde al sentimiento de «encogimiento vital» propio de épocas como la Antigüedad, el Medievo y el Renacimiento, en las que predominaba la mirada hacia un pasado que se reconocía y admiraba como modelo a seguir en todos los ámbitos. ${ }^{24}$ Tampoco responde a la sensación de «plenitud de los tiempos» ${ }^{25}$ que acompañó al nacimiento y desarrollo de un hombre moderno que, arropado por el pensamiento cartesiano y el primer «Positivismo» que supuso la obra de Francis Bacon, veía culminados en su época todos los intereses e ideales de progreso por los que se lucharon en el pasado. Si el «hombre-masa», henchido tanto de los ideales como de las materializaciones del progreso político y tecnológico presentes desde el siglo XVIII, no puede encuadrarse en ninguno de estos sentimientos vitales que señala Ortega es por su desapego al pasado. Obviamente, su confianza y autosatisfacción no muestran la nostalgia por el pasado que caracterizó a la época de «encogimiento vital»; pero, asimismo, esta seguridad tampoco le incluye en la «plenitud de los tiempos», pues esta última sensación, en tanto consciente de ser la culminación de un

\footnotetext{
22 Para una profundización en las teorías de Jürgen Habermas remitimos a dos de sus estudios, Problemas de legitimación en el capitalismo tardío ( Madrid, Cátedra, 1999) y Técnica y ciencia como ideología (Madrid, Tecnos, 2002).

${ }^{23}$ Op. cit., pp. 283-284. Obsérvense los vínculos que semejante lectura del «hombre-masa» como un ser vacío posee con la denuncia que Nietzsche hacía del nihilismo o triunfo de la nada. Asimismo, el «hombre noble» o «egregio» del que habla Ortega, muestra una fuerte conexión con el "superhombre» nietzscheano. Los vínculos con el filósofo alemán se hacen asimismo patentes en escritos como «El sobrehombre» (El Imparcial, julio 1908) y «Musicalia» (El Espectador III, 1921). Véase ORTEGA Y GASSET, José, Obras completas, vols. I (pp. 176-179) y II (pp.365-374), respectivamente.

${ }^{24}$ ORTEGA Y GASSET, José, La rebelión de las masas, Madrid, Tecnos, 2003, p. 147.

25 Op. cit., p. 149.
} 
camino, tenía siempre en mente al pasado, el punto de partida hacia el presente acabado que su época encarnaba ${ }^{26}$. La tristeza derivada de la relación con el pasado en ambos estados anímicos históricos -en el primero por ser un modelo insuperable, en el segundo por haberlo superado y dejar el futuro sin aspiración alguna-, otorgaba a los hombres la nobleza y la autocrítica necesarias para la comprensión y posible superación de los problemas de su tiempo. Pero el «hombremasa», al no vincularse de ningún modo con el pasado histórico, un pasado que concibe caduco y superado y del que no se siente culminación o heredero de sus logros, se encuentra en la desagradable a la par que confusa situación de enfrentarse a un futuro aún por realizar y en el que no sabe como manejarse al estar desprovisto de las armas que otorga el conocimiento histórico. «El resto de espíritu tradicional se ha evaporado. Los modelos, las normas, las pautas, no nos sirven. Tenemos que resolvernos nuestros problemas sin colaboración activa del pasado, en pleno actualismo- sean de arte, de ciencia o de política-. El europeo está solo, sin muertos vivientes a su vera; como Pedro Schlemihl ha perdido su sombra» 27 .

Pero, ¿cuáles son esas fuerzas de las que se siente el «hombre-masa»tan orgulloso como para olvidarse de las enseñanzas del pasado? ¿Qué fuerzas pueden enaltecer a la par que amenazar al individuo que las posee?

Todos los rasgos psicológicos que hemos ido señalando en el «hombre-masa», convertido en un «señorito satisfecho» ${ }^{28}$ por el panorama político, social e industrial en el que como tal se ha desarrollado, se completan y responden a las preguntas aquí planteadas al abordar un factor determinante en la gestación y evolución del hombre a lo largo de su historia, pero especialmente importante en la Edad Contemporánea si tenemos en cuenta la cantidad y calidad de los descubrimientos realizados en los últimos dos siglos. Semejante desarrollo no podía dejar de influir en la conformación ideológica del «hombre-masa»; de ahí que continuemos su disección tomando la técnica como hilo conductor en las reflexiones que siguen.

\section{LA TÉCNICA: NUEVO IDEAL HUMANO. MATEMATIZACIÓN DE LA REALIDAD, ESPECIALISMO, MECANIZACIÓN, HERMETISMO.}

Indudablemente, no hay nada más humano que la técnica. Desde los comienzos de la humanidad, la técnica ha acompañado a ésta en su evolución, dotándola de fuego, hogar, alimento, armas y medios de comunicación diversos. Pese a que la técnica es un fenómeno ligado al hombre y a su capacidad de modificar el entorno para su supervivencia, su fuerte desarrollo no ha ido siempre ligado a una pareja asimilación ideológica. La superación que la ciencia y tecnología actuales

${ }^{26}$ Op. cit., p. 155.

27 Op. cit., p.156

${ }^{28}$ Expresión con la que Ortega se referirá al síndrome que aqueja al «hombre-masa». Vid. «La época del señorito satisfecho» en Op. cit., pp. 233-247. 
han hecho respecto de las capacidades que el hombre tiene de manejarlas es una prueba de ello.

La época contemporánea vio marcado su ulterior desarrollo económico, político, social y espiritual en 1780, década en la que la Revolución industrial ya era una realidad consolidada en el que fue su país de origen, Inglaterra. Este fenómeno fue origen de una serie de transformaciones socio-económicas que explican su repercusión en la ideología del «hombre-masa». La aparición de la fábrica industrial como edificio urbano aglutinador de unos nuevos medios de producción financiados por capital privado, supuso el triunfo de los sistemas mecánicos como herramienta de trabajo y explotación, mostrando los anteriores procedimientos, movidos ya por el hombre ya por agentes motores naturales como el agua de los ríos o los animales, como insuficientes y caducos en un renovado panorama técnico que adelantaba grandes transformaciones económicas como la sustitución de la manufactura por el producto industrial. La consecuencia inmediata de esta revolución fue la migración masiva del campo a unas ciudades que se vieron considerablemente incrementadas en su población y extensión, así como transformadas en lo que respecta a sus clases sociales: es este el momento en que hacen su entrada en la escena histórica clases sociales como el proletariado y la burguesía industrial, así como una clase media formada por funcionarios, personal de servicios, oficinistas, etc...; las verdaderas protagonistas en todo el transcurso del siglo XX. Las nuevas ciudades industriales, acogieron el imparable desarrollo técnico no sólo en las fábricas, sino también en sus redes de transportes: la aparición del ferrocarril y la navegación a vapor comenzarían a formar parte del paisaje urbano contemporáneo. Este es el escenario donde habitan las multitudes y, por ende, el burgués u «hombre-masa». El crecimiento demográfico y las aglomeraciones que Ortega señala en su ensayo como circunstancias inseparables del «hombre-masa» pueden verse en estos primeros capítulos de la vida burguesa ${ }^{29}$.

Pero la irrupción y el predominio de la técnica van a traer consigo transformaciones que, aunque menos obvias a primera vista que aquellas que modificaron el aspecto físico de las ciudades, actuarían de forma definitiva sobre la configuración del sujeto contemporáneo. Nos referimos a cuestiones como la amplia y sistemática aplicación de la ciencia a los procesos de producción y a los diversos campos especulativos; y a la división y especialización del trabajo resultante de tal concepción.

La industrialización y la técnica a su servicio van a tener a la ciencia como principal instrumento y a la utilidad o aplicación práctica como su mayor finalidad. La ciencia encarnaba el ideal humano desde que la llustración instaurase la Razón como instrumento cognitivo necesario para el progreso del hombre en todos los ámbitos. La sistematización del conocimiento bajo este criterio racionalizador, or-

\footnotetext{
${ }^{29}$ Nos referimos a dos de los capítulos de La rebelión de las masas, «El hecho de las aglomeraciones» y «Un dato estadístico» (Op. cit., pp.121-132 y 171-178, respectivamente).
} 
denador, disciplinado, no se limitó a las ciencias en sentido estricto sino que también se aplicó a la cultura en toda su extensión. ${ }^{30}$ El modelo para la construcción de esta racionalización del mundo que fue el Siglo de las Luces procedía de las Ciencias naturales y su método teórico tradicional. ${ }^{31}$ Este proceder consiste en crear teorías en base a un criterio inamovible e irrefutable: la correspondencia con la realidad a la que se aproximan y que definen. Los medios para alcanzar semejante analogía especular son la matematización de la realidad y de sus objetos, de tal modo que éstos queden reformulados en principios abstractos de índole general, bajo los cuales se subsumen los rasgos particulares. Esta unificación del campo de estudio a partir de la cosificación de los objetos, implica la reducción de la realidad a unos principios generales que, por basar su verdad en la correspondencia con el mundo y por haber sido realizados por un sujeto que se supone neutral y objetivo, en sus apreciaciones, aparecen como inamovibles. La subjetividad queda anulada, así, en la construcción de estas teorías tradicionales a partir de las cuales se explica el mundo. Concebida de este modo, la realidad parece ser un sistema cerrado, una caja definitivamente configurada, necesaria, donde no hay lugar para el cambio o lo particular que constituye la historia y lo social: bajo esta cosificación de la realidad, todo esta previsto.

Semejante concepción teórica -a la que acertadamente Horkheimer contrapone su Teoría Crítica ${ }^{32}$-, que plantea al sujeto que la construye como neutral o inerte y reduce el mundo a generalizaciones casi divinas, es la que construye el mundo en el que se gesta el «hombre-masa». Éste responde a semejante planteamiento cosificador: su realidad es la masa indiferenciada, el colectivo donde reinan las generalizaciones en detrimento de lo individual; su carácter es conformista, inerte como consecuencia de la asimilación de una realidad estática y cerrada bajo los dictados del conocimiento y el progreso científicos; su participación histórica, por tanto, es nula, imposible en un contexto donde la voz individual queda

\footnotetext{
${ }^{30}$ Prueba de ello es la Encyclopedie ou Dictionnaire raisonné des sciences, des arts et des métiers, dirigida por dos de los principales protagonistas de la llustración francesa, Diderot y D'Alembert, y publicada en Paris entre 1751 y 1772 . El proyecto, que constó de diecisiete volúmenes de texto y otros once volúmenes para las láminas, constituyó una labor de democratización del conocimiento en sus distintos campos, tratándose cada uno de ellos con el rigor propio de una labor científica.

${ }^{31}$ En el texto de Max HORKHEIMER Teoría tradicional y teoría crítica (Barcelona, Paidós, 2000), obra que se considera fundacional de la Escuela de Frankfurt, se encuentra un análisis pormenorizado de los principios y funciones del método teórico procedente de las Ciencias naturales. Este método, el propio del Positivismo, es llamado tradicional en oposición a un modelo de Teoría Crítica que, a partir de la visión lógico-trascendental de Immanuel Kant y de la visión crítico-material de Karl Marx , tratará de aproximarse a la historia como una realidad dinámica, abierta y particular.

${ }^{32}$ La Teoría Crítica se establece en base a la inevitable relación dialéctica entre el sujeto y el contexto socio-histórico en el que se mueve: las teorías están determinadas por el contexto y éste a su vez lo está por las teorías que suscita. Semejante autodeterminación señala, en oposición a los principios sobre los que se basa la Teoría tradicional, que no hay neutralidad posible en la construcción teórica puesto que ésta se realiza por sujetos que interpretan la realidad en base a un contexto concreto y sus valores correspondientes. La eliminación por parte de la Teoría Crítica del componente abstracto y generalizador en la ordenación de la realidad por los sujetos inertes que construyen tradicionalmente teorías, permite concebir el mundo como algo orgánico y dinámico y, por tanto, abierto a la participación de los individuos en su construcción política e histórica.
} 


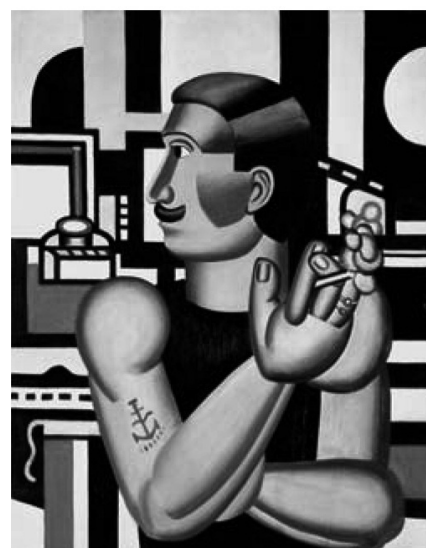

Figura 4: Fernand Léger, El mecánico, 1920.

deslegitimada frente a las verdades incuestionables que la ciencia y la técnica han establecido como ideología ${ }^{33}$.

Ortega es muy consciente del papel que la ciencia y la técnica han jugado en la conformación psicológica del «hombre-masa»; no en vano dedica a la cuestión en el ensayo que ocupa nuestro análisis dos capítulos al tema ${ }^{34}$.

El «hombre-masa» nace y se desarrolla en el contexto del crecimiento industrial y tecnológico; pero la inercia, el hermetismo y la inconsciencia histórica que constituyen su carácter le han impedido la asimilación del significado y de las consecuencias que conlleva semejante evolución científica ${ }^{35}$. Como bien hemos señalado, el «hombre-masa» es un ser ajeno al contexto en el que se desenvuelve. En este sentido, Ortega define al «hombre-masa» como «un primitivo, un Naturmensch emergiendo en medio de un mundo civilizado»36. «El «hombre-masa» no es consciente del desarrollo masivo que la técnica ha tenido en su tiempo; su crecimiento físico e intelectual, paralelo a tal progreso, junto a su carácter, desvinculado del pasado y del presente histórico, ha derivado en una asimilación de la técnica hasta el punto de considerarla naturaleza y no un producto de la civilización ${ }^{37}$. El «hombre-masa», rodeado de facilidades materiales y jurídicas, concibe los beneficios de esta «nueva naturaleza» como necesarios, como un derecho de su bienestar del que, en tanto obligatorio, no es responsable. Pero la realidad es que el «hombre-masa» no vive en ese estado de naturaleza tecnificado en el que se cree soberano por derecho divino; la técnica y ciencia de las que se desentiende son producto de la civilización, y ésta no es autosuficiente como la verda-

\footnotetext{
${ }^{33}$ HABERMAS, Jürgen, Ciencia y técnica como «ideología», Madrid, Tecnos, 2002.

34 «Primitivismo y técnica» y «La barbarie del "especialismo"». ORTEGA Y GASSET, José, La rebelión de las masas, pp.209-220 y 247-256, respectivamente.

${ }^{35}$ Op. cit., pp. 223-224.

${ }^{36}$ Op. cit., p. 213.

37 lbid.
} 
dera naturaleza sino que necesita de las responsabilidades que deben tener para con ella los hombres que la conforman ${ }^{38}$.

Semejante desapego que manifiesta el «hombre-masa» hacia la técnica, una de las causas -junto a la amnesia política, social, moral, etc... de las que está aquejado- del posible derrumbe de la civilización, podría parecer contradictorio si recordamos que la burguesía y la ciencia son dos fenómenos relacionados de forma muy íntima desde su aparición en escena a principios del siglo XVIII. La burguesía apareció como clase social a raíz de la industrialización de los núcleos urbanos y adquirió progresivamente el poder del que actualmente goza por su inmersión laboral en el mundo del desarrollo tecnológico. La técnica, por un lado, es el origen del bienestar material de esa parte burguesa dueña del poder de los medios de producción que integra esa gran clase constituida por los «hombres-masa», y la actitud poco deudora que éste manifiesta hacia ella resulta como poco sorprendente ${ }^{39}$. «El hombre-masa», principal protagonista y beneficiario del desarrollo que la ciencia y la industria han experimentado en los últimos dos siglos, se aleja de la técnica, -de la realización más humana que permite al hombre mejorar su existencia como tal-convirtiéndola en algo ajeno a su persona, en algo deshumanizado al «desfamiliarizarse ${ }^{40}$ drásticamente de ella. De nuevo, la sabiduría procedente de la memoria histórica queda desplazada frente a la amnesia y la fuerza sorda del hermetismo y de la inercia que rigen los comportamientos del «hombre-masa». El «hombre-masa», sin conciencia histórica, retrocede para situarse como un primitivo en la piel de la barbarie y, así caracterizado, proceder a la violenta conquista del mundo ${ }^{41}$.

La explicación de este primitivismo manifestado por el hombre en la era de la técnica se encuentra en el aparato conceptual de la misma así como en su funcionamiento.

La Revolución industrial inglesa se produjo gracias a una investigación científica que, desde un siglo antes, venía ensalzándose como la empresa colectiva de mayores alcances para la humanidad ${ }^{42}$, y que con el poder económico procedente del comercio y de la industria naval recibió su impulso definitivo. Los descubrimientos realizados en la física (Galileo, Huyghens, Pascal y Kepler hasta llegar a Newton), la biología (el sistema binomial de Linneo), la electricidad (Galvani, Volta) y la maquinaria industrial (máquinas de hilar, máquina de vapor), así como la cre-

${ }^{38}$ Op. cit., pp.221-222.

39 Op. cit., pp.216-217.

${ }^{40}$ Concepto que John Crispin considera más adecuado para referirse al problema de la deshumanización del arte planteado por Ortega en su ensayo de 1925. Vid. CRISPIN, John, La estética de las generaciones de 1925, Valencia, Pre-Textos, 2002, pp. 68-71.

${ }^{41}$ Ortega encuentra una clara materialización de las peligrosas consecuencias resultantes de la amnesia histórica que caracteriza a ese "primitivo-técnico» que es el «hombre-masa» en algunos de los principales movimientos políticos que azotaron Europa, el bolchevismo y el fascismo. Op. cit., p. 226.

42 Francis Bacon (1561-1626), con su concepción de una ciencia pública, financiada por el Estado y organizada de forma corporativa en aras de obtener los máximos beneficios sociales, fue considerado por los padres de la ciencia contemporánea (Boyle, Newton, Darwin) como el punto de partida del espíritu y trabajo científicos materializados en su época. 
ación de diversas instituciones consagradas a las ciencias aplicadas ${ }^{43}$, auguraban un futuro más que prometedor para el hombre y su nueva vida tecnificada, no sólo en Inglaterra, sino también en el resto de países europeos que pronto se incorporaron al desarrollo industrial.

Semejante desarrollo científico y económico, por la gran cantidad de descubrimientos teóricos y aplicaciones prácticas que generaba, estuvo acompañado por la necesidad de una mayor mano de obra, tanto en las fábricas industriales como en los laboratorios de investigación. Una tarea de semejantes dimensiones necesitaba de una producción muy organizada; consiguientemente, el trabajo se concebiría como un sistema, como una gran máquina en la que encajar cada una de las piezas de modo que no sacrificasen en tiempo y esfuerzo el rendimiento general del conjunto: se producía una división del trabajo y, así, nacía el trabajo en cadena, la especialización.

En La rebelión de las masas, Ortega identifica el primitivismo del «hombremasa» con la especialización del trabajo científico y, aunque se remite al siglo XIX como culmen de esta relación, es en el siglo XVIII donde, por todos los factores ya señalados, se encuentra las raíces de la problemática.

El progreso del conocimiento, recordemos, basado en el método científico de unificación de los campos mediante la matematización o abstracción de sus objetos de estudio, va a requerir, paradójicamente, que el trabajo se realice por partes, de forma fragmentada o dividida. De este modo es como nacen los técnicos $u$ hombres de ciencia, una casta superior dentro de la misma burguesía en la que podemos encontrar no sólo cargos exclusivamente científicos sino todo tipo de profesiones. Para Ortega, «el hombre de ciencia actual es el prototipo del hombremasa »44, o más bien, de los especialistas que genera la ciencia y su método de trabajo surge el «hombre-masa», el máximo representante de la conjunción primitivismo-técnica: «un bárbaro moderno» ${ }^{45}$.

La especialización conlleva necesariamente una reducción del conocimiento general en pos de una profundización en un campo concreto: del saber enciclopédico o global desarrollado en el siglo XVIII, se pasará de forma progresiva a lo largo del XIX al saber determinado o fragmentado, del hombre civilizado al hombre primitivo. El conocimiento amplio, que implica el esfuerzo intelectual de relacionar sus distintos componentes para articularlos en la comprensión del todo, así como fomenta el interés o curiosidad vital por la realidad y los acontecimientos circundantes -motor del hombre histórico, inmerso en su tiempo-, se ve sustituido por un

${ }^{43}$ En 1662, y bajo la influencia del pensamiento de Bacon, se fundaba ya en Inglaterra la primera institución dedicada a la ciencia aplicada: la Royal Society. El objetivo era la mejora de las «artes mecánicas» o manuales, es decir de los oficios que se contraponían a las artes liberales o intelectuales y en los que se incluían disciplinas como la construcción, la metalurgia o la agricultura. Semejante polémica clasificatoria de las artes arrancaba ya en el siglo XV con el Renacimiento italiano.

${ }^{44}$ Op. cit., p. 249.

45 lbid. 


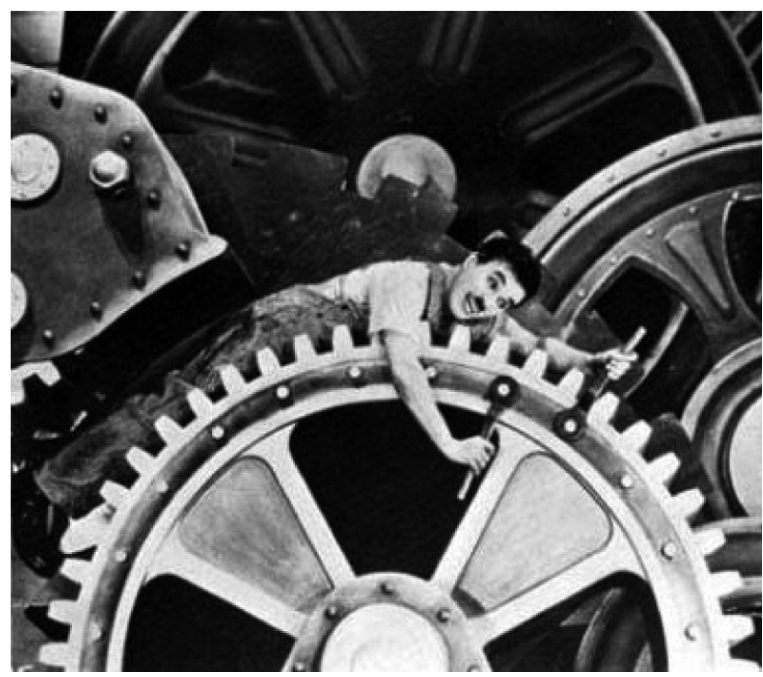

Figura 5: Fotograma de Tiempos modernos, Charles Chaplin, 1936.

cultivo exhaustivo de ámbitos de conocimiento muy concretos. Este estudio pormenorizado de una pequeña parcela de la realidad, tratada al margen de las relaciones que pueda mantener con el resto de las parcelas con las que conforma el todo, genera un sujeto calificado como especialista y/o hombre de ciencia pero cuyo conocimiento permanece ajeno a los fundamentos y principios de la ciencia a la que se remite. Alejado de las relaciones y tensiones que configuran el mundo y su aprehensión intelectual, este hombre, el «hombre-masa», ejerce su trabajo sin apenas esfuerzo, sin establecer relaciones, de forma mecánica, como el perfecto engranaje que exige el trabajo en cadena que sustenta a las nuevas investigaciones científicas. ${ }^{46}$ De nuevo, el «hombre-masa» se ve actuando por inercia, como un mecanismo a las órdenes invisibles de su relojero: los dictados de la ideología que la ciencia y la técnica han configurado para el Estado y el sistema capitalista. El «hombre-masa», condecorado con el galardón de ser un hombre de ciencia, resulta ser en realidad la pieza prototipo perfecta para un progreso y bienestar humanos en los que participa intensamente pero desde el anonimato, desde un puesto limitado y reproducido de forma estandarizada en todos los hombres de su misma ocupación, desde la incomunicación y el distanciamiento de un saber aislado tanto del contexto general del que procede como del contexto particular en el que va a repercutir su aplicación. El distanciamiento despersonalizado con que acomete su trabajo es el mismo que con el que se enfrenta a la realidad circundante ${ }^{47}$.

Es a partir de un conocimiento parcelado y aislado de todo lo que no sea sí mismo como se configura la psicología de ese ser ensimismado, despersonalizado

${ }^{46}$ Op. cit., pp.251-252.

${ }^{47}$ Op. cit., p. 219. 
y mecánico que es el hombre de ciencia, el especialista o el «hombre-masa». Es en su visión limitada a un sólo campo en detrimento del resto, donde se halla el origen del hermetismo intelectual: el «hombre-masa», crecido en su autoestima por formar parte de la nueva religión redentora de la humanidad que es el progreso, interpreta que su conocimiento limitado y concreto es sabiduría, asume sus opiniones como las verdades absolutas que necesariamente ha de poseer el nuevo abanderado de la Ciencia que se considera. Es por ello por lo que este hombre especializado es calificado por Ortega de «sabio-ignorante» "48, condición que le lleva a encerrarse herméticamente en la única realidad que conoce y, en consecuencia, a despreciar y negar de forma sistemática el resto: el mundo termina donde acaban sus conocimientos, más aún, el mundo sólo puede construirse y comprenderse bajo los mismos. Es este ensimismamiento y hermetismo el que conducirá, en el plano artístico, a la disociación entre el público y el arte moderno, entre la tradición comprensible y la modernidad incomprensible que, por extensión se tornará inadmisible y rechazada.

Pues, esta autosuficiencia intelectual que rezuma el «hombre-masa» se traduce en la violenta soberbia con que opina en y de todos los ámbitos, en la indocilidad que manifiesta hacia opiniones diferentes a las suyas, en el empleo de tópicos y prejuicios en sus argumentaciones, alejadas de la humildad y el esfuerzo que requieren el verdadero conocimiento. Ésta es la rebelión que teme Ortega, «no que el vulgar crea que es sobresaliente y no vulgar, sino que el vulgo proclame e imponga el derecho de la vulgaridad, o la vulgaridad como un derecho" , ${ }^{49}$ reclamación que implica el ataque continuo y el intento de disolución de las amenazas que constituyen los destellos de individualidad expresados por las minorías.

Semejante comportamiento, tan alejado de la curiosidad intelectual, del deseo de conocimiento que convierte al hombre en algo activo y dinámico, convierte al «hombre-masa», en un ser unívoco al poseer la misma naturaleza hermética que el resto de sus análogos. El burgués se muestra, de este modo, como una caja cerrada, como un producto seriado, como un ser predecible y ya escrito, unívoco, en todos sus comportamientos y falsas opiniones; su pasividad e inercia, alentada por las muchedumbres en las que se integra, lo alejan de lo humano, del individualismo creador que caracteriza al sujeto responsable y en diálogo con su tiempo.

Realizada ya la caracterización psicológica del «hombre-masa», podemos, a modo de conclusión, retomar las cuestiones planteadas en La deshumanización del arte en relación con el problema del público.

Recordemos que la rama del público que rechazaba sistemáticamente el «arte nuevo» estaba representada en su mayor parte por la clase burguesa, por unos «hombres-masa» detractores de la «realidad contemplada», la metáfora, la ironía

${ }^{48}$ Op. cit., p.252.

49 Op. cit., p. 200. 


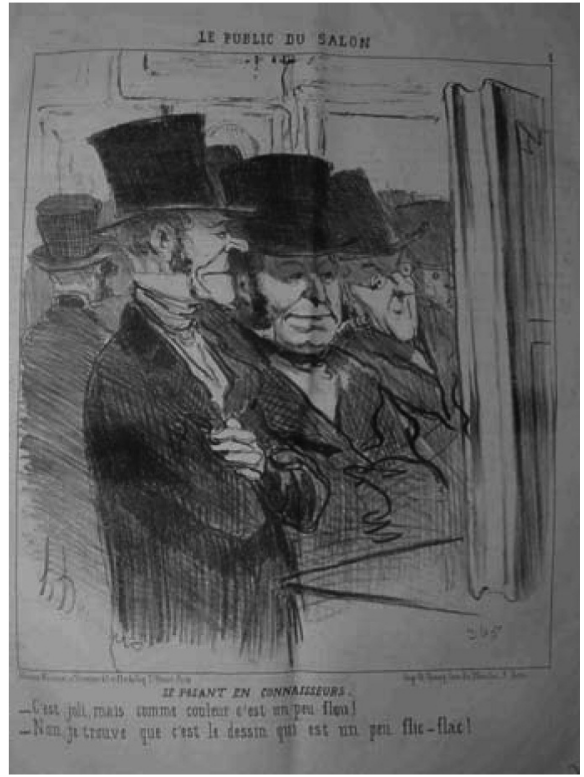

Figura 6 Honoré Daumier «Le Public du Salon. Se posant en connaisseurs» en Le Charivari, Ca.1852.

y el juego que las «nuevas» obras presentaban ${ }^{50}$. El carácter equívoco que estas creaciones manifestaban ante un espectador conformado psicológicamente de forma uniforme, unívoca, hermética frente a cualquier acontecimiento ajeno a su especializado conocimiento, no podía sino derivar en el más violento rechazo por parte de un público cultivado en la soberbia y los tópicos. Ante las creaciones de un arte «nuevo» que se desconocía por completo, el burgués u hombre de ciencia satisfecho de su estrechez de miras no podía sino pensar para sí mismo: el arte «lleva al hospital. ¿Para qué sirve? No sirve para nada, pues se lo reemplaza por la mecánica, que produce mejor y más rápido»51. La equivocidad, complejidad y, con frecuencia, ambigüedad del arte moderno exaspera a un hombre educado en la utilidad, la parcelación cognitiva y la mecanización propias de la especialización científica que constituye su ocupación, fuente de orgullos y objeto de indiferencia. Este rechazo sistemático de lo ajeno al conocimiento y alcance intelectual propios revela un hermetismo deudor del sentimiento nihilista generalizado que Nietzsche denunciara en el siglo precedente. «Todo anti no es más que un simple y hueco no»52. Una negación que caracterizaría al público del nuevo arte moderno desde la creación de ese espacio expositivo para los expulsados, el Salon des Refusés, y

\footnotetext{
50 Para un análisis más pormenorizado de estos conceptos, fundamentales en la articulación de la idea de deshumanización del arte de Ortega y Gasset, remito a mi breve estudio -»José Ortega y Gasset y La deshumanización del arte» en Espacio, Tiempo y Forma, Serie VII, Historia del Arte, t. 20-21, 2007-2008, pp. 285-299.

${ }^{51}$ Definición que Gustave Flaubert, crítico por excelencia de la burguesía y su mediocridad intelectual, da de Arte en su Diccionario de los lugares comunes, Buenos Aires, Libros del Zorzal, 2004, p.17.

52 ORTEGA Y GASSET, José, La rebelión de las masas, Madrid, Tecnos, 2003, p. 223.
} 
que vendría a constituirse como el principal elemento al que las vanguardias históricas dirigirían sus más furibundos ataques. El rechazo del arte moderno por parte del público alimentaría el rechazo del público -esto es, de la burguesía, sus ideales, principios y gustos estéticos- por parte del arte moderno. Y es ahí donde Ortega y Gasset introduce su interpretación: un arte deshumanizado es el arte que ha nacido en ese contexto poblado de «hombres-masa». Un arte incomprendido que se complace en su rechazo y que potencia su incomprensión alejándose de la comodidad y de las convenciones del universo definitivamente explicado, encajonado y conservado en sus estilos y tradiciones. 